\title{
Cem anos de endemias e epidemias
}

\author{
A century of endemic and epidemic diseases
}

Rita Barradas Barata 1

1 Departamento de Medicina Social/FCM, Santa Casa de São Paulo, rua Cesário Motta Jr. 61 5o andar, 01221-020 São Paulo, SP cemedsoc@santacasasp. org.br
Abstract This paper traces, in brief, a broad view in the main epidemics and endemics that attacked the population in the State of São Paulo during the 20th century. The facts are presented contained in five defined periods starting from outstanding facts of the national life. It tries to find the occurrence of the problems of health in the social political and economical context of each period. The information are based on revision, not exhausting, of some scientific journals of the public health and medicine subjects. The considered periods are: from the beginning of the century to the end of the "Republica Velha", the "getulista" period, the "golden years" from 1945 to 1964, the military dictatorship and the current period after the fall of the dictatorship. For each period it describes the epidemic situation and the main endemics for which there were available information. Given the limited extension of an article, it was not possible to deepen the aspects related to the appearance of each one of the problems, nor the details of its control. We opted for the construction of a panel that makes possible to the readers a landscape vision of the 20th century. The list of bibliographical references can be useful to those who want to deep themelves in the different themes. Key words Epidemiological Profile; Endemics and Epidemics; Infectious Diseases; Needs and Problems of Health
Resumo Este ensaio traça, resumidamente, um panorama das principais epidemias e endemias que acometeram a população do estado de São Paulo, no século XX. Os fatos são apresentados agrupados em cinco períodos, definidos a partir de fatos marcantes da vida nacional. Situa a ocorrência dos problemas de saúde no contexto econômico social e político de cada período. As informações baseiam-se em revisão, não exaustiva, de alguns periódicos científicos da área de saúde pública e medicina. Os periodos considerados são: do início do século ao final da República Velha, o período getulista, a redemocratização de 1945 a 1964, a ditadura militar e o período atual após a queda da ditadura. Para cada período descreve-se a situação epidemiológica das principais endemias e epidemias e para as quais havia dados ou informações disponíveis. Dada a extensão limitada de um artigo, não foi possível aprofundar os aspectos relacionados ao surgimento de cada um dos problemas, nem os detalhes de seu controle. Optou-se pela construção de um painel que possibilitasse aos leitores uma visão de conjunto do século XX. A lista de referências bibliográficas poderá ser útil àqueles que desejarem se aprofundar nos diferentes temas tratados.

Palavras-chave Perfil Epidemiológico; Endemias e Epidemias; Doenças Infecciosas; Necessidades e Problemas de Saúde 


\section{Introdução}

Antes de iniciar, propriamente, este ensaio são necessárias algumas aclarações. Primeiramente, o sentido em que serão utilizados os termos endemia e epidemia neste texto. Em segundo lugar a fixação do âmbito geográfico e temporal ao qual este ensaio estará restrito. Um terceiro aspecto diz respeito à construção do ensaio e os materiais nela utilizados. Finalmente, o marco teórico ao qual este estudo está filiado.

Vamos utilizar os termos endemia e epidemia em sua acepção mais tradicional, isto é, aquela que predominou desde os escritos hipocráticos, na Antigüidade, até a emergência da estatística e sua influência na epidemiologia já no século XIX, e que se baseia em uma diferença de qualidade entre as doenças endêmicas e as epidêmicas. Tendo em vista que essas acepções convivem ainda hoje com as novas concepções baseadas no aspecto quantitativo, consideramos que poderíamos fazer uso das mesmas.

Tradicionalmente foram classificadas como doenças endêmicas aquelas que apresentavam entre suas características epidemiológicas a variação espacial, isto é, uma distribuição espacial peculiar associada a determinados processos sociais ou ambientais específicos. Do mesmo modo eram classificadas como epidêmicas as doenças que apresentavam variações no tempo, isto é, apresentavam concentração de casos em períodos determinados, sugerindo mudanças mais ou menos abruptas na estrutura epidemiológica.

A concepção quantitativa passou a considerar ocorrência endêmica aquela que corresponde ao comportamento usual da enfermidade numa população específica em um determinado momento histórico e ocorrência epidêmica uma alteração significante, brusca e temporária no número de casos de uma doença em uma determinada população em certo período histórico (Foucault, 1977).

Qualquer classificação apresenta uma dose de arbitrariedade, sendo facilmente constatável o aparecimento de surtos epidêmicos de doenças classificadas como endêmicas bem como a observação de doenças epidêmicas que se tornam endêmicas em determinadas circunstâncias. Apesar disto tentaremos nos ater a problemas de saúde produzidos pelas chamadas endemias e aos episódios epidêmicos de doenças infecciosas com interesse em saúde pública.
O ensaio irá se referir apenas às ocorrências no estado de São Paulo, tendo em vista a escassez de tempo para elaborá-lo e a maior facilidade de acesso às informações referentes a São Paulo por parte do autor. As informações trabalhadas referem-se ao século XX.

Tendo em vista a dificuldade de obter séries históricas confiáveis acerca da ocorrência dessas doenças para o período de interesse, optamos por trabalhar com informações veiculadas em artigos científicos publicados nos seguintes periódicos: Annaes da Faculdade de Medicina de São Paulo, Annaes Paulistas de Medicina e Cirurgia, Arquivos de Higiene e Saúde Pública, Revista de Saúde Pública, Cadernos de Saúde Pública, Revista da Sociedade Brasileira de Medicina Tropical, Informe Epidemiológico do SUS.

Não se trata evidentemente de pesquisa exaustiva, havendo uma série de publicações que poderiam ser consultadas mas que não o foram por impossibilidade de tempo. Além disso, limitamos nosso material a aquilo que mereceu a atenção dos epidemiologistas em cada época. Para a caracterização das transformações sociais em São Paulo neste século utilizamos principalmente a coleção Nosso Século e a coleção História da Vida Privada no Brasil.

Finalmente, o ensaio foi construído buscando articular as transformações ocorridas, desde o início do século, na sociedade paulista $e$ as endemias e epidemias que acometeram a população de São Paulo, assumindo a teoria da determinação social do processo saúde-doença como referencial teórico. Esta opção implica entender a ocorrência das endemias e epidemias como produto social, da mesma forma que a produção do conhecimento científico relativo a elas e as respostas sociais, ou práticas sanitárias de controle (Laurell, 1983; Breilh et al., 1990; Castellanos, 1997; Paim, 1997)

A forma ensaio foi escolhida como a mais adequada para o tipo de discussão que se pretende fazer e também pelo tipo de material disponível para a construção do artigo.

\section{Primeiro período: $1900-1930$}

Do início da colonização em 1532 até meados do século XVIII o crescimento demográfico da província havia sido lento e apenas uma pequena parte do território estava ocupado. $\mathrm{O}$ café que começa a ser plantado no Vale do Pa- 
raíba, ainda dependendo de mão-de-obra escrava, vai progressivamente ocupando novos espaços no planalto (SEADE, 1992).

O século XIX assiste a intenso desmatamento, fluxos migratórios internos e externos, construção de ferrovias e grande crescimento econômico. Uma nova classe dirigente surge desse movimento, muito mais poderosa e opulenta do que os antigos barões do açúcar. Esta nova classe, mais urbana do que os antigos proprietários rurais contribui para a modificação da paisagem urbana. Na última década do século XIX foram criados 41 novos municípios ao longo dos trajetos das estradas de ferro (Monbeig, 1981).

Os sinais de enriquecimento do estado eram visíveis embora a cotação internacional do café caísse constantemente. A safra de 19011902 superou o consumo em 1 milhão de sacas (Nosso Século, 1980). Durante todo o período da Primeira República a produção cafeeira será mantida e expandida às custas da política econômica do governo federal garantindo preços aos produtores e subsidiando as exportações agravando consideravelmente o endividamento nacional.

Grandes cidades começam a surgir como espaço para novas possibilidades de vida, atraindo principalmente os imigrantes estrangeiros descontentes com as condições de vida e trabalho nas fazendas de café (Marins, 1998).

Parte desses trabalhadores migravam na tentativa de fugir das epidemias de febre amarela e varíola que acometiam de maneira avassaladora muitas das cidades do interior. A última década do século XIX e a primeira do século XX tiveram as atenções das autoridades sanitárias voltadas para a elucidação dos mecanismos de transmissão e o controle dessas duas doenças.

As formas de ocupação do espaço agrário e também do espaço urbano determinaram condições extremamente favoráveis para a ocorrência de doenças transmitidas por vetores, doenças de transmissão hídrica e doenças de transmissão respiratória. Dentre as doenças transmitidas por vetores destacam-se nesse período a febre amarela, a peste, a malária, as leishmanioses cutâneo-mucosas e a doença de Chagas.

Em Santos a mortalidade por febre amarela, em 1892 chegou a 6,2\% da população. Daí a doença irradiou-se para o interior do estado fazendo algumas vítimas na capital, geralmente na hospedaria dos imigrantes (Piza,
1964). Na região cafeeira de Ribeirão Preto o surto se inicia em outubro de 1901 generalizando-se no ano seguinte. Os médicos da cidade não aceitavam a teoria da transmissão vetorial da doença e impediam a tomada das medidas de controle preconizadas por Emílio Ribas. Dada a gravidade do surto, parte da população bem como a própria administração municipal abandonaram a cidade e a comissão da Inspetoria Sanitária do estado pôde impor as medidas de controle: isolamento hospitalar dos doentes, expurgo domiciliar com piretro, destruição dos criadouros com o uso de querosene, proteção telada para portas e janelas (Figueiredo, 1996). Realizaram-se também obras de engenharia sanitária como a canalização de córregos e a drenagem das margens dos rios além da coleta de lixo urbano reduzindo a densidade dos vetores.

Emílio Ribas aproveitou a ocorrência desse surto para realizar experimentos que comprovassem a transmissão vetorial da febre amarela visto que muitos médicos e cientistas consideravam que a doença era transmitida pela água contaminada. Esta visão era reforçada pelos avanços obtidos no controle após a realização de obras de saneamento básico. Emílio Ribas obteve larvas do vetor na cidade de Itu, onde não havia casos de febre amarela, e enviou os mosquitos adultos a São Simão, onde estava ocorrendo a epidemia, fazendoos picar indivíduos doentes. Após 16 dias estes mesmos mosquitos picaram seis pessoas: o próprio Emílio Ribas, Adolfo Lutz, um assistente dos dois e três imigrantes italianos que nunca haviam estado em áreas endêmicas. Os três imigrantes apresentaram os sintomas da doença. Ribas leu o resultado de seus experimentos na sessão de 19 de fevereiro de 1909 da Society of Tropical Medicine and Hygiene presidida por Patrick Manson (Ribas, 1909).

Após 1903 não houve mais registros de casos e a doença só voltou a ser registrada em São Paulo em 1928 durante a ocorrência de uma epidemia no Rio de Janeiro, desaparecendo a seguir (Piza, 1964).

Durante toda a década a importação de alfafa e trigo da Argentina esteve associada à ocorrência de surtos de peste, inicialmente no porto de Santos e depois nas localidade cortadas pela estrada de ferro Santos-Jundiaí, inclusive na capital. Os casos registrados em São Paulo ocorriam nos bairros em que estavam localizados os armazéns de estocagem de grãos. Em 1908 a peste aparece em Iguape em 
conseqüência de um surto iniciado no porto de Paranaguá. Oswaldo Cruz foi chamado a Santos para orientar o controle da doença instituindo a compra de ratos para posterior eliminação. Rapidamente a população mais pobre passou a criar ratos para vendê-los ao Serviço Sanitário. Na capital, os casos foram mais freqüentes entre 1900 e 1903 declinando nos anos subseqüentes (Piza, 1964).

A malária era doença extremamente freqüente em todo o planalto paulista bem como no litoral do estado embora as informações disponíveis não sejam muito precisas. Há relatos de epidemias com acometimento de 40 a $85 \%$ da população das localidades atingidas. O aparecimento de casos novos vai acompanhando a progressão da fronteira agrícola, principalmente da produção cafeeira, em seu avanço para o oeste (Lutz, 1903; Machado, 1919).

A epidemia de leishmaniose tegumentar eclode em 1907 e 1908 durante a construção da Estrada de Ferro Noroeste disseminandose por toda a Alta Sorocabana, Alta Paulista e região noroeste do estado seguindo a penetração do homem e a derrubada das matas. A designação "úlcera de Bauru" surgiu em decorrência desse surto visto que o acampamento dos trabalhadores localizava-se nessa cidade. Durante a década de 1910 ocorrem surtos importantes em Bauru; 1914, Pirajuí; 1917, Birigüi e Penápolis e Araçatuba, em 1919. Os casos ocorrem entre trabalhadores que derrubam as matas, moradores de vilas e povoados recém-instalados bem como entre os sitiantes e fazendeiros (Pessoa, 1941).

Em outubro de 1910 Carlos Chagas apresenta à Academia Nacional de Medicina sua monografia sobre "Nova entidade mórbida do homem" (Chagas, 1910). Teodoro Bayma descreve os primeiros casos da doença, em São Paulo, em 1914, época em que é feito o primeiro levantamento entomológico no estado (Coutinho, 1962). A única zona então infestada pelo Triatoma infestans era a região norte do estado, área de plantio de café e cana de açúcar (Wanderley, 1993). Assim como no caso da malária, a doença passará a ocupar as outras regiões do estado acompanhando a "onda verde" da expansão dos cafezais.

Entre as endemias rurais importantes a última a aparecer em São Paulo foi a esquistossomose cujos primeiros casos autóctones foram registrados em Santos em 1923. Nessa ocasião foram identificados 11 casos sem que se conhecesse a espécie de transmissor envolvida. Não foi atribuída maior importância à descoberta visto que se acreditava não haver condições propícias para a instalação da endemia (Piza, 1965).

Apesar da crise dos preços do café, a farta mão-de-obra imigrante que afluía para as cidades, as facilidades de crédito e a modernização dos transportes deram impulso definitivo à concentração industrial. As indústrias vão transformando as cidades. Cafeicultores paulistas como os Prado e os Álvares Penteado começam a diversificar seus investimentos dando origem aos impérios industriais. Mas, a maioria dos industriais em São Paulo constituía-se de europeus enriquecidos nas atividades comerciais como os Jafet, Crespi, Street e Scarpa no ramo de tecelagem; Siciliano e D’Andrea nas máquinas agrícolas; Duchen, nos biscoitos; Klabin no papel; Ramenzoni na confecção de chapéus e os Matarazzo em inúmeros ramos industriais (Nosso Século, 1980).

No início do século, São Paulo tinha 240 mil habitantes e para cada dois italianos havia um brasileiro. Ao final da década a população atingia 450 mil dos quais cerca da metade eram imigrantes europeus (Nosso Século,1980). As condições precárias de habitação predominavam tanto na área central quanto nos bairros operários dos arrabaldes: Brás, Moóca, Cambuci, Bom Retiro, Barra Funda, Pari e Bexiga (Marins, 1998). A maioria da população apinhava-se em cortiços e casa geminadas, com precárias condições sanitárias. A higiene era precária mesmo entre as famílias ricas e era muito freqüente a mortalidade entre menores de um ano em todas as classes.

As condições de vida do proletariado eram muito precárias e cerca de $50 \%$ dos trabalhadores da indústria eram crianças. As greves contra a carestia eram constantes nas primeiras décadas do século, destacando-se o movimento dos portuários de Santos em 1905, dos ferroviários paulistas em 1906, e as greves gerais de 1907 e 1917, todas elas organizadas pelo movimento anarquista.

Dentre as doenças de transmissão hídrica a febre tifóide é a mais emblemática desse período. Conhecida desde o final do século XIX era uma das mais importantes causas de mortalidade na capital. Adolfo Lutz elucidou a etiologia tifóide das chamadas febres paulistas. Os mananciais não protegidos, a contaminação da água de abastecimento, o leite, os le- 
gumes e as frutas contaminadas favoreciam o aparecimento de grande número de casos (Pestana, 1918). Em 1914 e em 1920-1921 ocorreram importantes epidemias na capital atingindo principalmente os bairros operários do Belenzinho, Moóca e Penha (Vieira, 1922). Na epidemia de 1924-1925, o coeficiente de incidência chegou a 196 casos por 100.000 habitantes apesar da subnotificação de casos ocorrida no período da revolução de 1924 quando a cidade foi bombardeada. Todos os bairros periféricos apresentaram cifras acima da média da cidade e na Penha e no Butantã as taxas ultrapassaram 790 casos por 100.000 habitantes (Vieira, 1926).

A aglomeração urbana favorecia também a ocorrência de doenças de transmissão respiratória tais como a tuberculose, a varíola, a difteria, a escarlatina e a meningite meningocóccica. A tuberculose, além de transmitida por via aérea, era adquirida também pelo consumo de leite contaminado não pasteurizado. A varíola ocorre em casos esporádicos e benignos nesse período, gerando inclusive muitos debates acerca de seu diagnóstico tendo em vista a ausência de casos graves como era comum em outras partes do mundo. A difteria, introduzida na década de 1990 do século XIX por imigrantes europeus, disseminou-se rapidamente, tornando-se endêmica nos meses de outono e inverno. A escarlatina também era bastante freqüente respondendo por 964 internações no Hospital de Isolamento, entre 1900 e 1908 (Piza, 1964).

Os primeiros casos de meningite meningocóccica foram diagnosticados em fevereiro de 1906 em quatro pacientes removidos da Hospedaria dos Imigrantes no Brás, para o Hospital de Isolamento. Entre 1906 e 1913 foram registrados mais 53 casos, sendo $47 \%$ deles entre estrangeiros mas apenas $16 \%$ na Hospedaria. A letalidade, na ausência de tratamento específico, chegava a $45 \%$ dos casos (Junqueira, 1914). Entre 1921 e 1925 ocorre uma epidemia provocada por cepas do soro A francês, com incidência 3 a 4 vezes maior do que a observada no período endêmico. Durante toda a década de 1920 a letalidade oscila entre 30 e 60\% (Assumpção, 1929).

Mas, nenhuma epidemia marcou tanto a vida da capital quanto a epidemia de gripe conhecida como gripe espanhola, que provocou inúmeras mortes em 1918 acometendo inclusive o presidente eleito Rodrigues Alves. A epidemia teve início em São Paulo no final de ou- tubro e em meados de dezembro já havia perdido força. Nesse curto espaço de tempo, entre 6 e 8 semanas, foram notificados 116.777 casos (22,32\% da população da capital) e registrados 5.331 óbitos. O número total de casos foi estimado em 350 mil o que corresponderia a 2/3 da população paulistana. Em decorrência da epidemia foram suspensas as atividades escolares, fecharam-se os bares e os cinemas, interromperam-se as atividades industriais e comerciais. Embora toda a população tenha sido envolvida no episódio, as maiores taxas de incidência foram observadas nos bairros periféricos e nas áreas centrais onde predominavam os cortiços e a aglomeração humana facilitava o contágio (Bertolli, 1986).

Durante todo esse período o "complexo cafeeiro" estimulou múltiplas atividades e assumiu várias facetas, sendo ao mesmo tempo um empreendimento agrícola, mercantil, industrial e financeiro além de motor da urbanização. Apesar das flutuações no preço internacional, a política econômica de desvalorização cambial e compra de estoques permitiu a expansão continuada da "onda verde" até que em 1929 os preços caem vertiginosamente e a crise se instala, ainda mais profundamente com o crash da Bolsa de Valores de Nova York.

\section{Segundo período: 1930-1945}

O ano de 1930 marca uma inflexão importante na história nacional com a ascensão de Getúlio Vargas ao poder e a quebra da política "café com leite" que até então havia privilegiado os interesses dos cafeicultores paulistas e dos pecuaristas mineiros. Para São Paulo, a mudança nas orientações da política econômica tiveram muitas repercussões.

Com a crise de 1929 muitas indústrias foram desativadas, as demissões dos operários tornaram-se rotina, e os salários sofreram reduções de até $50 \%$ de seu valor agravando as já precárias condições de vida do proletariado urbano.

A centralização do poder no nível federal permitirá a emergência de um mercado nacional integrado, base para a implementação de uma política de substituição das importações no setor industrial.

A oligarquia paulista, sentindo-se alijada do poder permanece na oposição ao novo governo insurgindo-se em 1932 através de uma revolta armada que será derrotada. 
O processo de modernização e a retomada da industrialização refletem-se na criação de instituições de pesquisa e tecnologia que vão constituir a base para o progresso do estado. Em 1934, Armando de Sales Oliveira cria a Universidade de São Paulo reunindo as faculdades de Direito, Medicina, Filosofia e Ciências Humanas, Ciências Naturais e Química.

No início da década de 1940 São Paulo já é o maior centro industrial da América Latina e a capital tem mais de um milhão de habitantes.

Nesse período, o eixo dinâmico da economia passa a ser a produção industrial para o mercado interno tendo em vista as dificuldades para a expansão das exportações durante o período da depressão econômica e da II Guerra Mundial (Nosso Século, 1980).

O crescimento e a diversificação industrial ocorrem com maior rapidez em São Paulo ao mesmo tempo em que a agricultura passa por um período de diversificação e modernização. A monocultura do café é substituída paulatinamente pelo plantio de cana, algodão, arroz, feijão, milho e trigo.

Os problemas urbanos se avolumam e ganham destaque nas lutas populares a questão da moradia, a falta de água, a carestia, o crescimento da inflação.

O quadro sanitário, em relação às doenças endêmicas e epidêmicas permanece praticamente inalterado. As mesmas doenças que haviam dominado o cenário no período anterior se fazem presentes agregando-se a elas a emergência de novos problemas ou de antigos sob novas roupagens.

Durante a década de 1930 são feitos os primeiros relatos de casos de leptospirose em São Paulo (Magaldi, 1963). Embora a doença fosse conhecida desde a década de 1910 ela não havia sido registrada no estado. As precárias condições de saneamento e a presença constante de ratos certamente possibilitaram o surgimento dos casos. A partir daí os surtos seriam freqüentes nos meses de verão.

A febre amarela que esteve ausente desde 1906, volta a se manifestar, agora sob a forma silvestre, isto é, na ausência do vetor urbano. Os casos aparecem em novembro de 1935, na divisa com Minas Gerais e Goiás. Em 1936 são registrados 996 casos e em 1937, 351 casos, todos nas áreas novas, de ocupação recente, na região noroeste do estado (Pestana, 1937).

A leishmaniose que até então havia provocado surtos nas áreas em desmatamento apa- rece na capital produzindo casos periurbanos e suburbanos em clusters familiares (Pestana e Pessoa, 1940).

As taxas de incidência da malária são extremamente altas durante todo o período, acometendo a população de todo o estado, com maior intensidade no litoral e nas áreas novas de ocupação mais recente próximas à divisa do estado com o Mato Grosso e o Paraná. Há três grandes epidemias nesse período: 1935, 1940-1941 e 1945. A incidência que normalmente variava entre 250 e 350 casos por 100.000 habitantes chega a 476/100.000 hab. em 1935, 713 em 1940, 2.422 em 1941 e 690 em 1945. As taxas ultrapassam os 5 mil casos por 100.000 hab. nos municípios do litoral com exceção da cidade de Santos (Barata, 1998). As epidemias coincidem com períodos de disseminação dos criadouros de A. darlingi ao longo dos rios Tietê, Paraná e Paranapanema e de seus principais afluentes, que se sucedem a cada cinco anos.

Outra doença extremamente freqüente no meio rural paulista nesse período é o tracoma. A inexistência de água tratada e a aglomeração intradomiciliar nas moradias rurais facilita a transmissão (Ferreira, 1948).

$\mathrm{Na}$ área urbana, principalmente nas cidades maiores, continuam ocorrendo casos de difteria, meningite meningocóccica, escarlatina, sarampo, febre tifóide, tuberculose. Um novo perigo, que se tornaria muito presente no período seguinte começa a fazer sua aparição: a poliomielite.

\section{Terceiro período: 1946-1964}

Com o final da era Vargas e a re-democratização do país, o estado tenta restabelecer os princípios liberais na condução da economia agora sob forte influência dos norte-americanos. A política de livre importação tem como principais efeitos o esgotamento das divisas acumuladas durante o período de guerra e a estagnação da indústria nacional. A desvalorização do cruzeiro provoca maciças entradas de capital estrangeiro mas aumenta a inflação piorando as condições de vida das massas urbanas.

Entre 1945 e 1964 o processo de industrialização vive momentos decisivos na substituição das importações passando a produzir bens de consumo duráveis e bens de capital (Mello e Novaes, 1998). 
No início da década de 1950 a ocupação territorial do estado está completa, restando apenas $1 \%$ da cobertura florestal original na escarpa atlântica, no vale do Ribeira e no pontal do Paranapanema. São Paulo continua sendo o principal produtor dos principais produtos agrícolas do país embora mais de 50\% da população já esteja residindo na área urbana. A urbanização acelerada decorre de um duplo movimento: o aumento da oferta de empregos nas indústrias e a transformação do trabalho no campo com a destruição do sistema de "colonato" e o surgimento do trabalhador volante ou "bóia-fria" que deixa de residir nas fazendas vindo engrossar as periferias dos núcleos urbanos (Barata, 1998).

Durante esse período doenças como a malária, as leishmanioses, a febre amarela e a doença de Chagas tem sua incidência diminuída ou estabilizada uma vez que já não há florestas a derrubar nem espaços novos a conquistar. A ocupação agrícola ou industrial do solo vai transformando as condições de produção dessas doenças tornando o risco de transmissão menos presente. Em 1950 ocorre a última epidemia de malária significativa. São 261 casos por 100.000 habitantes afetando menos de 10 municípios do extremo noroeste do estado. Durante a década as taxas vão oscilar entre 30 e 50 até que tenha início, em 1959, a campanha para a erradicação (Barata, 1998).

Surgem focos autóctones de esquistossomose nos municípios de Ourinhos, Palmital e Ipauçu, região onde é encontrada a Biomphalaria glabrata, hospedeiro intermediário com maior potencial para a manutenção de focos. Novos focos são detectados ainda no vale do Ribeira e vale do Paraíba, região que se tornará endêmica para a doença, tendo a transmissão associada principalmente à lavoura do arroz em alagados (Chieffi e Waldman, 1988).

Em 1950 a capital já tem 2 milhões e setecentos mil habitantes e não pára de crescer. A imigração internacional, praticamente interrompida após a década de 1930, dá lugar a intenso movimento migratório interno. A greve geral de 1953 vê surgirem novas lideranças sindicais vinculadas ao partido socialista ou comunista, fora da influência populista do PTB. Em 1954, 1 milhão de trabalhadores entram em greve face à política econômica catastrófica.

O governo de JK com seu otimismo desenvolvimentista e o programa de metas marcam a segunda metade da década de 1950. A indús- tria automobilística, instalada na região do ABC paulista, torna-se o símbolo da modernização do país. Entre 1955 e 1961 são feitos grandes investimentos na construção de estradas de rodagem, transportes aéreos, siderurgia, eletricidade e outros investimentos de base (Nosso Século, 1980).

Próximo ao final da II Guerra, em 1945, inicia-se em São Paulo nova epidemia de doença meningocóccica que irá se estender até 1951. Embora a incidência tenha aumentado bastante em relação ao período endêmico, esta epidemia parece ter passado praticamente desapercebida das autoridades e da população havendo sido "descoberta” já no início dos anos 60 pelos professores Ary Schmid e Ayrosa Galvão ao realizarem exercícios de epidemiologia descritiva com seus alunos de Saúde Pública. Novamente parecia se tratar de uma epidemia provocada pelo sorotipo A visto que os grupos mais afetados foram os menores de 4 anos e os adolescentes de 15 a 19 anos. A incidência passou de 2,34 casos por 100.000 hab. em 1944 para 9,41 em 1945; 20,17 em 1946; 25,00 em 1947; 18,00 em 1948; 8,76 em 1949; 6,01 em 1950 e 4,80 em 1951 (Schmid e Galvão, 1961).

A década de 1950 marca o surgimento das grandes epidemias de poliomielite. Com o progressivo saneamento básico dos bairros intermediários e periféricos da cidade, as crianças deixavam de estar expostas aos poliovírus desde a idade pré-escolar tornando-se especialmente vulneráveis ao contágio durante as férias de verão, em idades mais avançadas, o que aumentava o risco de aparecimento de formas paralíticas. Assim, contraditoriamente, o saneamento básico, numa época em que não existiam as vacinas, tornava o surgimento de casos paralíticos mais freqüentes.

Outra doença importante no âmbito urbano era o sarampo que por sua intensa infectividade e patogenicidade afetava praticamente todas as crianças, em torno dos 7 anos de idade ou mesmo antes. Para parte delas, ter sarampo era parte "natural" da infância mas, muitas, acometidas por diferentes graus de desnutrição, morriam antes de completar 5 anos de idade em conseqüência das complicações provocadas pela doença.

Em 1962 a inflação chega a 52\% ao ano, a população já é majoritariamente urbana, e os problemas de moradia, educação, saúde, saneamento e transporte urbano só se agravam. A mudança de uma economia primordialmente agrícola para outra industrial é acompanha- 
da no plano sanitário pelo crescimento de doenças ligadas ao padrão de vida urbano como as cardiovasculares, as neoplasias e os acidentes e a redução das doenças infecciosas, embora estas continuassem a representar grande desafio às instituições de saúde (Nosso Século, 1980).

\section{Quarto período: 1965-1984}

O novo governo militar instalado após o golpe de 64 tem como primeira meta o expurgo do populismo. Mudadas as regras do jogo político, tem início o novo modelo econômico centrado no fortalecimento do capitalismo privado e fomento ao capital estrangeiro. $\mathrm{O}$ combate à inflação será feito a partir do congelamento salarial embora em uma conjuntura de pleno emprego e crescimento econômico.

A política salarial favorece a concentração de rendas levando grandes parcelas do proletariado urbano à pauperização, aumentando as desigualdades sociais. Entre 1970 e 1973 a economia vive uma fase de euforia batendo recordes de crescimento. As exportações cresceram 32\% respaldando a expansão industrial interna. No final da década, a crise do petróleo e a escalada do processo inflacionário internacional põem fim a esta fase de crescimento e lança a economia em profunda crise (Nosso Século, 1980)

No estado de São Paulo, o processo de urbanização se acelera durante toda a década de 1960 e a população urbana passa de $62 \%$ em 1960 a $80 \%$ em 1970.

A redução constante da população rural durante todo o período associada aos esforços de controle de endemias como a malária e a doença de Chagas modificam o perfil epidemiológico no estado.

A campanha de erradicação da malária executada entre 1960 e 1964 começa a mostrar resultados e a incidência da doença reduz-se consideravelmente. As taxas de incidência caem em todo o território e a transmissão natural torna-se residual (Barata, 1998). Iniciada a fase de consolidação da campanha de malária, em 1964, os recursos são deslocados para o "arrastão" contra a doença de Chagas. Em 1968 , passa-se a utilizar o "expurgo seletivo" como forma de controle dos triatomíneos e em 1973 tem início o processo de estratificação epidemiológica das localidades rurais. Em 1978 é interrompida a transmissão natural (Wanderley, 1993).
A esquistossomose ganha maior proeminência nesse contexto de redução da malária e da doença de Chagas. A endemia encontra-se em franca expansão surgindo focos autóctones em vários pontos do interior do estado. Em 1970, são localizados focos mantidos por $B$. straminea em Americana e em 1982 identifica-se um foco ativo em Ubatuba. Entre 1978 e 1983 ocorrem cerca de 20 mil casos novos por ano sendo que apenas 10\% são autóctones. Há três regiões consideradas endêmicas no estado: o vale do Paraíba, o vale do Ribeira e a região de Marília. São consideradas potencialmente endêmicas a Grande São Paulo, as regiões de Santos, Campinas e Ribeirão Preto. As regiões do oeste do estado: Bauru, Araçatuba, Presidente Prudente e São José do Rio Preto e a região de Sorocaba são consideradas indenes à despeito da presença de hospedeiros intermediários inicialmente classificados como $B$. tenagophila. Em 1981, Paraense identifica esses hospedeiros intermediários como B. ocidentalis, espécie resistente à infeção pelo schistossoma explicando assim a ausência de focos nessas áreas (Chieffi e Waldman, 1988).

O desenvolvimento industrial segue três eixos geográficos de crescimento. O primeiro, na região central em torno de Campinas, concentra grandes indústrias com incorporação tecnológica intensiva e produção de meios intermediários. O segundo, na região norte do estado, caracteriza-se pela agroindústria de laranja, carne, soja, café e cana de açúcar. O terceiro, na região da sorocabana, reúne atividades industriais produtoras de bens intermediários e agroindústrias (Barata, 1998).

Em 1970, cerca de $72 \%$ da força de trabalho está constituída por assalariados dos quais $88 \%$ trabalham mais de 40 horas semanais e $55 \%$ ganham menos de dois salários mínimos. Os salários reais sofrem queda acentuada atingindo em meados dos anos 70 valores inferiores aos do início dos anos 50 (Barata, 1988).

A cidade de São Paulo será palco da maior epidemia de doença meningocóccica já registrada. Entre 1970 e 1977 serão registrados cerca de 35 mil casos na população paulistana. Até 1973, praticamente se repete o que havia ocorrido na última epidemia, isto é, as autoridades sanitárias ignoram o fato, embora a incidência tenha aumentado cerca de 10 vezes. Entretanto, em 1974 com a superposição de duas ondas epidêmicas, pelos sorotipos A e C, a incidência chega a 169,10 casos por 100.000 habitantes, não podendo mais ser ignorada. 
Mais uma vez, as populações residentes na periferia serão as mais afetadas. A censura à imprensa escrita, ao rádio e à televisão impedem que sejam divulgados os números de casos e óbitos e, principalmente, que se estabeleçam conexões entre o crescimento da pobreza e das desigualdades provocado pelo modelo econômico e o surgimento da epidemia. Apenas uma extensa campanha de vacinação promovida em 1975 é capaz de deter o avanço da epidemia que mesmo assim ainda levará 24 meses para se extinguir (Barata, 1988).

Da capital a doença se espalhou atingindo outras cidades grandes do interior e do litoral do estado. Na vigência da epidemia começam a surgir casos com manifestações clínicas de encefalite no litoral sul atingindo sete municípios da Baixada Santista e 13 municípios do vale do Ribeira. Em janeiro de 1975 são registrados 8 casos de encefalite por 100.000 habitantes e a cifra chegará a 90 casos por 100.000 hab. em março de 1976. Em 1978 é isolado o agente causal dessa epidemia, identificado como vírus Rocio provavelmente transmitido por culicídeos. Entre 1978 e 1983 ainda serão registrados 80 casos nessa região. A investigação epidemiológica concluiu pela introdução recente do agente na região e pela possível origem em Iguape, facilitada pelas condições climáticas, topográficas, cobertura vegetal, atividade humana predominantemente rural, residência próxima à mata, rios e lagoas, e pela presença de grandes contingentes de operários que haviam trabalhado na construção da rodovia Transamazônica e retornaram à região após 1971 (Iversson, 1977, 1980, 1984).

Além das epidemias já mencionadas, o período é marcado por diversos surtos de febre tifóide localizados em bairros periféricos da capital e pela persistência de casos de poliomielite, difteria, sarampo, e outras doenças infecciosas da infância.

Com o licenciamento da vacina Salk e em seguida da vacina Sabin o interesse pelo controle da poliomielite aumentou e a Secretaria de Estado da Saúde iniciou, em 1969, a realização de campanhas bianuais de imunização dos menores de 4 anos visando ao controle da doença além de intensificar esforços para aumentar a cobertura vacinal dos menores de 1 ano na imunização de rotina. Estudos conduzidos por Stewien, Barbosa e Rosenburg (1977) com alunos da rede de ensino municipal demonstraram que cerca de $50 \%$ do grupo de 7 a 14 anos estava imunizado contra os três tipos de vírus. As crianças residentes na área central da cidade apresentavam menor imunidade do que as residentes nas áreas intermediárias e periféricas, fato este explicado pela exposição natural ao vírus selvagem nas regiões intermediárias e periféricas dadas as piores condições de saneamento básico aí vigentes.

Entre 1964 e 1980 nosso capitalismo combinou concentração de riqueza, mobilidade social, concentração de renda, ampliação rápida dos padrões de consumo moderno, diferenciação e massificação. A pobreza espiritual, a miséria moral e a despolitização social darão seus frutos na "década perdida" e se prolongarão praticamente até o final do século.

\section{Quinto período: 1985-1999}

Nos anos 80 e 90 a estagnação econômica, o processo inflacionário e o desemprego crescente rompem os mecanismos básicos de reprodução social interrompendo a mobilidade social observada no período anterior e restringindo o consumo. A transformação no mundo do trabalho é de tal ordem que os trabalhadores informais ultrapassam percentualmente os trabalhadores formais.

O agravamento da crise financeira e as várias tentativas de ajuste efetuadas nesse período acabaram por produzir um aumento do desemprego urbano principalmente no setor industrial, atingindo de trabalhadores não qualificados a profissionais de nível superior.

As políticas de ajuste visavam principalmente à proteção da acumulação da riqueza privada concentrando ainda mais a renda nacional. Com a globalização invertem-se as bases da reprodução social: faltam empregos, a mobilidade torna-se descendente, acirra-se a concorrência e a violência torna-se um recurso cotidiano para a sobrevivência (Mello e Novaes, 1998).

Nesse cenário novas doenças surgem e antigas reaparecem sob novas formas. No início dos anos 80 aparecem em São Paulo, os primeiros casos de AIDS, importados dos Estados Unidos. Rapidamente, contra as expectativas de muitos sanitaristas, a doença irá se tornar um dos mais importantes problemas de saúde pública. Os casos inicialmente acometendo grupos restritos da população, disseminam-se entre as diferentes classes sociais e nos anos 90 seu impacto é tal que produz redução na esperança de vida masculina, rever- 
tendo os ganhos que, desde o início do século, o controle das doenças infeciosas e carenciais tinham propiciado.

Em 1984 outra doença nova surge, agora no interior do estado: é a febre purpúrica do Brasil. Crianças entre 3 meses e 8 anos de idade apresentam quadros agudos e muitas vezes fatais, de febre purpúrica, que no início são confundidos com meningococcemia. A investigação epidemiológica, entretanto, demonstra que não há a concomitância entre esses casos e a presença de meningite meningocóccica nessa população havendo então a suspeita de uma doença nova. Após cerca de 8 semanas, os casos cessam sem que tenha sido possível esclarecer a etiologia. Dois anos depois, em 1986, novo surto ocorre em Serrana, estabelecendo-se então a relação entre o surgimento dos casos e a ocorrências de epidemias de conjuntivite provocadas por Haemophilus aegypti (Kerr-Pontes e Ruffino Netto, 1991).

Em 1985, a febre amarela faz sua re-introdução no estado. Em maio são notificados 3 casos em Presidente Prudente e Santo Expedito, aparentemente, todos importados do Mato Grosso. A investigação epidemiológica decorrente dessas notificações identifica 44 focos de Aedes aegypti em Presidente Prudente, indicando assim o risco de transmissão urbana da doença e de possíveis epidemias de dengue (Coimbra et al., 1987).

Em 1989 é identificado um surto de malária em usuários de drogas injetáveis na cidade de Presidente Prudente com 12 casos. Os afetados são jovens do sexo masculino, residentes na periferia e empregados no comércio ou na construção civil (Lo et al., 1991). No ano seguinte novo surto ocorre em Bauru com 21 casos confirmados e 119 suspeitos (Barata, 1993). Durante a década de 1990 outros surtos ocorrerão em Araçatuba, Presidente Prudente, Bauru e outras cidades do interior, constituindo-se essa modalidade de transmissão em um problema recorrente desde então.

A ameaça de re-introdução da febre amarela urbana não se concretizou, mas os primeiros casos autóctones de dengue foram registrados em 1987 em Araçatuba e Guararapes. Ocorreram apenas 46 casos devido à pronta ação da SUCEN no controle dos surtos. Mas, em 1990 o dengue provocou grande epidemia na região de Ribeirão Preto com 3.038 casos (Pontes et al., 1991). Inquérito sorológico realizado em 1991 mostrou que 23.000 indivíduos haviam sido infectados. Em 1991 as epi- demias se sucederam nas cidades médias do interior atingindo as regiões de Barretos, Catanduva, São José do Rio Preto e Ribeirão Preto. Nos anos seguintes a transmissão mantémse controlada voltando a surgir grandes epidemias de 1995 em diante (Donalísio, 1999).

Uma nova doença aparece em 1993 na região metropolitana. Em Juquitiba são identificados 3 casos de síndrome pulmonar por hantavírus com dois óbitos. Os vírus são do tipo Muerto Canyon que haviam produzido casos nos EUA. Sorologia feita em soroteca obtida de roedores capturados entre 1981 e 1983 na capital mostrou $14 \%$ de positividade. O exame do soro de 409 pacientes com suspeita de leptospirose em 1990 mostrou oito soropositivos para hantavírus demonstrando assim que já havia circulação do agente na população murina e humana (Simões et al., 1994). Durante os anos 90 novos surtos serão identificados em diferentes locais do interior do estado.

O verão de 1994 dá início aos surtos de cólera no litoral sul. A ingestão de mariscos e pescados contaminados produz surtos familiares em São Vicente atingindo posteriormente Santos, Praia Grande, Cubatão e Guarujá. Em seis meses são investigados 3.600 suspeitos confirmando-se, laboratorialmente, $70 \mathrm{ca}-$ sos. Os casos ocorrem em áreas de extrema pobreza e sem as mínimas condições de saneamento (CVE, 1994).

Outra endemia que faz seu retorno ao estado, durante a década de 1990, é a leishmaniose tegumentar, apresentando-se agora como doença de áreas periurbanas submetidas a processos de desmatamento para loteamento, nas quais os vetores apresentam adaptação domiciliar (Corte et al., 1996). Já no final da década, ocorrerá um surto de leishmaniose visceral em Araçatuba demonstrando que antigos dogmas não resistem às transformações sociais. A doença que era considerada inexistente no estado, se manifesta em área que sofreu grande transformação econômica substituindo a criação de gado pelo plantio da cana, na qual se emprega, temporariamente, grande contingente de mão-de-obra migrante durante a colheita.

$\mathrm{O}$ aumento da cobertura vacinal de rotina e a realização de campanhas nacionais de intensificação durante os anos 80 reduziram consideravelmente a ocorrência das doenças evitáveis por vacinação. O saneamento básico contribuiu para tornar raridade os casos de febre tifóide e fez com que as diarréias deixassem de ser uma causa importante de morbidade e 
mortalidade. A poliomielite, cuja transmissão foi interrompida em decorrência desses dois grupos de medidas, foi considerada erradicada do continente americano.

O sarampo, doença com uma das maiores taxas de infectividade e patogenicidade conhecidas, apresentava, em São Paulo, aumento cíclico a cada dois ou quatro anos a despeito da vacinação de rotina realizada em menores de um ano e reforçada aos 15 meses. Em 1987 a Secretaria de Estado da Saúde optou por realizar campanha de vacinação indiscriminada para crianças de 9 meses a 14 anos de idade. Inquérito sorológico subseqüente mostrou que havia apenas 3\% de suscetíveis entre a população de 1 a 14 anos. Em 1992 nova campanha foi realizada entre as crianças de 1 a 10 anos de idade, utilizando a vacina tríplice viral. O impacto dessas medidas foi imediatamente sentido com o desaparecimento dos óbitos por sarampo e a intensa redução no número de casos. Entretanto, na década de 1990, as coberturas vacinais contra sarampo estiveram sempre abaixo de $90 \%$ propiciando o acúmulo de quantidade importante de suscetíveis. Em 1996, após 10 anos com baixas incidências, surge uma grande epidemia com registro de 57.659 casos suspeitos dos quais 21 mil foram confirmados laboratorialmente. As áreas mais atingidas foram a região metropolitana, Campinas e Ribeirão Preto. Cerca de $47 \%$ dos casos acometeram indivíduos de 20 a 29 anos embora o maior risco fosse verificado entre os menores de 5 anos (CVE, 1997).

\section{Conclusão}

Este breve recorrido pela história das epidemias e endemias em São Paulo durante o século XX evidencia que, apesar dos avanços técnico-científicos e das transformações econômicas, sociais e políticas, vivenciadas pela sociedade paulista, o controle das doenças infeciosas, endêmicas e epidêmicas não tem sido fácil de obter.

A história nos mostra que ao invés de existir um processo linear e relativamente simples de transição epidemiológica, no qual as chamadas doenças de pobreza são substituídas pelos males da modernidade, o que se observa é um quadro complexo de alterações, mudanças, adaptações e emergências típicas dos fenômenos vivos. A relação entre as populações de homens, vetores e agentes etiológicos é bastante complexa e não parece estar no horizonte, para os próximos anos, a miragem de uma vida livre de infeções. Talvez esse não seja um fato totalmente negativo, uma vez que, de certo modo, ele prova a vitalidade do mundo no qual vivemos e as inúmeras possibilidades plásticas dos seres vivos, que no processo de construção e reprodução de sua vida como espécie e como gênero, criam normas de vida saudáveis e doentes.

Realmente assustador é o fato, hoje comum às grandes cidades do continente americano, de ter como principal causa de morte entre adolescentes e adultos jovens os homicídios, sintoma inequívoco, da violência urbana e de nossa incapacidade de reconstruir o tecido social esgarçado pela falta de solidariedade, pela competição desenfreada, pela desigualdade vergonhosa, pela perda dos valores humanos mais elementares. 


\section{Referências bibliográficas}

Assumpção Lucas 1929. Estudo epidemiológico e bacteriológico da meningite cerebro-espinhal epidêmica na cidade de São Paulo. Revista de Biologia e Hygiene 2(1):5-33.

Barata LCB; Andriguetti Maria TM; Matos MR 1993. Surto de malária induzida entre usuários de drogas injetáveis. Revista de Saúde Pública 27(1):9-14.

Barata RB 1988. Meningite: uma doença sob censura? Editora Cortez, São Paulo.

Barata RB 1998 Malária e seu controle. Editora Hucitec, São Paulo.

Barbosa V; Stewien KE; Rosenburg C 1977. Estado vacinal, tipo de habitação e nível cultural da mãe e sua relação com o estado imunitário à poliomielite em amostra de escolares do município de São Paulo. Revista de Saúde Pública 11:330-337.

Bertolli C 1986. Epidemia e sociedade. A gripe espanhola no município de São Paulo. Dissertação de mestrado, Departamento de História da Faculdade de Filosofia, Letras e Ciências Humanas da USP.

Breilh J; Granda E; Campaña A; Costales P; Páez R e Yépez J 1990. Deterioro de la vida: un instrumento para análisis de prioridades regionales en lo social y la salud. Corporación Editora Nacional. Quito.

Castellanos PL 1997. Epidemiologia, saúde pública, situação de saúde e condições de vida. Considerações conceituais. In Barata RB. Condições de vida e situa cão de saúde. Abrasco, Rio de Janeiro.

Chagas C 1910. Nova entidade mórbida do homem. Archivo da Sociedade de Medicina e Cirurgia de São Paulo 1(5):255-292.

Chieffi PP e Waldman, EA 1988. Aspectos particulare do comportamento epidemiológico da esquistossomose mansônica no estado de São Paulo, Brasil. Cadernos de Saúde Pública 4(3):257-275.

Coimbra TLM; Iversson LB; Spir M; Alves VAF; Boulos M 1987. Investigação epidemiológica de casos de febre amarela na região noroeste do estado de São Paulo, Brasil. Revista de Saúde Pública 21(3):193-199.

Corte AA; Nozawa MR; Ferreira MC; Pignatti MG; Rangel O; Lacerra SS 1996. Aspectos eco-epidemiológicos da leishmaniose tegumentar americana no município de Campinas. Cadernos de Saúde Pública 12(4):465-472.

Coutinho JO 1962. Contribuição ao estudo da epidemiologia da doença de Chagas. Arquivos de Higiene e Saúde Pública 27(94):317-330.

CVE 1994. Cólera. Relatório da divisão de Vigilância Epidemiológica do ERSA 52. Secretaria de Estado da Saúde de São Paulo.

CVE 1997. A epidemia de sarampo em São Paulo. Secretaria de Estado da Saúde de São Paulo.

Donalísio MR 1999. O dengue no espaço habitado. Editora Hucitec, São Paulo.

Ferreira NG 1948. Grandes endemias. Arquivos de Higiene 19:19-23.

Figueiredo LTM 1996. A febre amarela na região de Ribeirão Preto durante a virada do século XIX: importância científica e repercussões econômicas. Revista da Sociedade Brasileira de Medicina Tropical 29(1): 63-76.

Foucault M 1977. O nascimento da clínica. Editora Forense Universitária, Rio de Janeiro.
Fundação SEADE, 1992. Atlas de população do estado de São Paulo. Imprensa Oficial, São Paulo.

Iversson LB 1977. Epidemia de encefalite por arbovírus na região sul do estado de São Paulo, Brasil, em 1975 e 1976. Aspectos da distribuição cronológica e geográfica dos casos. Revista de Saúde Pública 11:375-388.

Iversson LB 1980. Aspectos da epidemia de encefalite por arbovírus na região do vale do Ribeira, São Paulo, Brasil, no período 1975-1978. Revista de Saúde Pública 14: 9-35.

Iversson LB 1984. Encefalite na região do vale do Ribeira, São Paulo, Brasil no período pós-epidêmico, 1978 1983. Revista de Saúde Pública 18: 323-332.

Junqueira M 1914. Meningite cerebro-espinhal a meningococcus. Contribuição para sua epidemiologia em São Paulo. Annaes Paulista de Medicina e Cirurgia 2: 42-63.

Kerr-Pontes Lígia RS e Ruffino Netto A 1991. Estudo epidemiológico da febre purpúrica brasileira. Epidemia em localidades do estado de São Paulo 1986. Revista de Saúde Pública 25(5):375-380.

Laurell AC 1983. A saúde-doença como processo social. In Nunes, ED Medicina Social: aspectos históricos e teóricos. Editora Global, São Paulo.

Lo SS; Andrade JCR; Condino MLF; Alves MJCP; Semerghini MG 1991. Malária em usuários de drogas de administração endovenosa associada à soropositividade para HIV. Revista de Saúde Pública 25(1):17-22.

Lutz A 1903. Mosquitos e malária das florestas. Centralblatt f. Bakteriologie, Parasitenkund U. Infektions Krankheiten XXXIII(4). Cópia mimeografada pertencente ao arquivo da SUCEN.

Machado OM 1919. Epidemia de impaludismo na usina Esther e Cosmópolis e sua prophylaxia. São Paulo. Serviço Sanitário do Estado. Boletim no 7.

Magaldi C 1963. Incidência, prevalência e distribuição das leptospiroses no Brasil. Arquivos de Higiene e Saúde Pública 28(97):187-197.

Marins PCG 1998. Habitação e vizinhança: limites da privacidade no surgimento das metrópoles brasileiras. In Novaes FA (coord.) História da vida privada no Brasil. Companhia das Letras, São Paulo.

Mello JMC e Novaes F 1998. Capitalismo tardio e sociabilidade moderna. In Novaes FA (coord. geral). História da vida privada no Brasil. Companhia das Letras, São Paulo.

Monbeig P 1981. Pioneiros e fazendeiros de São Paulo. Editora Hucitec, São Paulo.

Nosso Século 1980. Vol. I. Editora Abril Cultural, São Paulo.

Paim JS 1997. Abordagens teórico-conceituais em estudos de condições de vida e saúde: notas para reflexão em ação. In Barata RB. Condições de vida e situação de saúde. Abrasco, Rio de Janeiro.

Pessoa SB 1941. Ensaios sobre a distribuição geográfica de algumas endemias parasitárias em São Paulo. Arquivos de Higiene e Saúde Pública 11:7-25.

Pestana BR 1918. A febre typhoide em São Paulo. Annaes Paulistas de Medicina e Cirurgia 9(5):123-136 e 9(7):149-164.

Pestana BR 1937. Considerações epidemiológicas a respeito da febre amarela e da febre amarela silvestre. $A n$ naes Paulistas de Medicina e Cirurgia 34(5):441-485. 
Pestana BR; Pessoas SB 1940. Leishmaniose tegumentar autóctone no município de São Paulo. Annaes Paulistas de Medicina e Cirurgia 40 (1):71-72.

Piza JT 1964. Esboço histórico da incidência de algumas moléstias infectuosas agudas em São Paulo. Arquivos de Higiene e Saúde Pública 29(99):7-46.

Piza JT 1965-1966. A esquistossomose em São Paulo. Arquivos de Higiene e Saúde Pública 30/31(103/110): 6-24.

Pontes RJS et al. 1991. Epidemia de dengue em Ribeirão Preto, São Paulo, Brasil. Revista de Saúde Pública 25 (4):315-317.

Ribas E 1909. A extinção da febre amarela no estado de São Paulo e na cidade do Rio de Janeiro. Arquivos de Higiene e Saúde Pública 1(1): 21-28.

Schmid A e G ALA 1961. Alguns aspectos epidemiológicos da meningite meningocóccica no municí- pio de São Paulo. Arquivos de Higiene e Saúde Pública 26:15-39.

Simões ML; Teixeira MG; Araújo FA 1994. Hantavírus. Informe Epidemiológico do SUS jul/dez: 37-48.

Stewien KE; Barbosa V; Rosenburg C 1977. Níveis de imunidade contra a poliomielite em amostra de escolares do município de São Paulo. Revista de Saúde Pública 11:270-278.

Vieira FB 1922. Estudo epidemiológico da febre typhoide em São Paulo. Epidemia de 1920-1921. Annaes Paulistas de Medicina e Cirurgia 10(4):90-116.

Vieira FB 1926. Febre tifóide em São Paulo 1924-1925. Estudo epidemiológico. Annaes da Faculdade de Medicina de São Paulo 1:347-381.

Wanderley DMV 1993. Controle do Triatoma infestans no estado de São Paulo. Revista de Sociedade Brasileira de Medicina Tropical 26(Supl. III):17-25. 